\title{
PSYCHIATRIC MORBIDITIES IN PATIENTS OF COPD AND BRONCHIAL ASTHMA ATTENDING OPD OF TERTIARY CARE HOSPITAL
}

Ab. Majid Gania1, Junaid Nabi², Javaid Ahmad Malik3, Ab. Wahid Khan ${ }^{4}$

${ }^{1}$ Assistant Professor, Department of Psychiatry, SKIMS MCH, Bemina.

${ }^{2}$ Senior Resident, Department of Psychiatry, SKIMS MCH, Bemina.

${ }^{3}$ Associate Professor, Department of Chest Medicine, SKIMS MCH, Bemina.

${ }^{4}$ Professor, Department of Psychiatry, SKIMS MCH, Bemina.

\section{ABSTRACT}

\section{BACKGROUND}

Chronic pulmonary diseases are a global health problem and the number of patients being treated in primary care settings is increasing. The prevalence of a life-time diagnosis of asthma has increased in all age groups. There has been a dramatic shift in the conceptualization and treatment of asthma and COPD in the last 50 years. Psychiatric disorders, especially anxiety disorders, are very common in patients with asthma and COPD. Anxiety is also common in COPD and is related to some of the same factors described for asthma including the psychological response to the experience of breathlessness as well as side effects of beta-agonists. Since there is paucity of relevant data from Kashmir, this study was designed to find the co morbidity in patients of COPD and Asthma in a tertiary care teaching hospital in Srinagar, Kashmir.

\section{METHODS}

Sixty successive patients presents with history of thirty each of asthma and COPD who fulfilled inclusion and exclusion criteria were taken up for the study and administered the Hamilton depression rating scale (HAM-D) and Hamilton Anxiety rating scale (HAM-A) scales for evaluation of depressive disorder and anxiety disorder. Each patient was informed about the purpose of interview; his/her consent was obtained and strict confidentiality was ensured. General description, demographic data and psychiatric history were recorded using semi structured Proforma and HAM-A and HAM-D.

\section{RESULTS}

Out of sixty cases of COPD and Bronchial Asthma, 50\% of the patients were in the age group of 66-80 followed by 35\% in age group of 81-85 years. This could suggest that COPD and Bronchial Asthma is a problem of old age. There were predominantly more males (65\%) than females (35\%) in our study. Representations of gender, religion, family type and marital status have been found to be in accordance with socio-demographic profile of our country. Out of sixty cases of COPD and Bronchial Asthma, 35\% of the patients were educated up to the primary level and 50\% had poor social support. This reflects that low literacy rate along with presence of social support are factors of importance in COPD and Bronchial Asthma.

\section{DISCUSSION}

Depression was found in $35 \%$ of patients while anxiety disorder was found in majority of patients of $65 \%$.

\section{KEYWORDS}

COPD, Asthma, Depression, Anxiety.

HOW TO CITE THIS ARTICLE: Gania AM, Nabi J, Malik JA, et al. Psychiatric morbidities in patients of COPD and bronchial asthma attending OPD of tertiary care hospital. J. Evolution Med. Dent. Sci. 2016;5(19):920-924, DOI: 10.14260/jemds/2016/214

\section{INTRODUCTION}

Chronic pulmonary diseases are a global health problem and the number of patients being treated in primary care settings is increasing. The prevalence of a life-time diagnosis of asthma has increased in all age groups. Links between psychological factors and allergic disorders have been observed in clinical practice for centuries.[1] There has been a dramatic shift in the conceptualization and treatment of asthma in the last 50 years or so. Acute exacerbations are a characteristic clinical expression of asthma and chronic obstructive pulmonary disease (COPD) and account for a significant amount of health care costs.

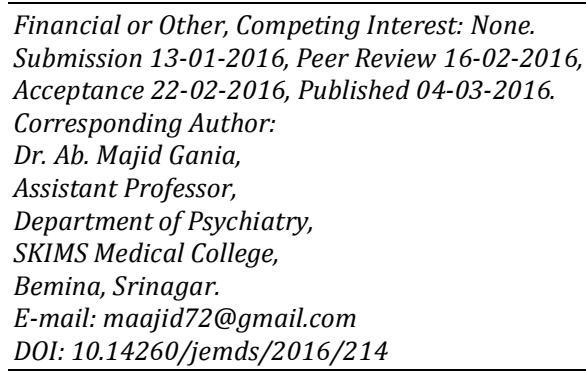

After hypertension, asthma is the most common chronic disease in the United States, affecting $5 \%$ to $7 \%$ of the population. Psychiatric disorders, especially anxiety disorders, are very common in patients with asthma. In youth with depression, asthma severity is increased relative to those with asthma alone.[2] In adults with asthma, mental health problems are also associated with poor asthma control.[3] Pulmonary function tends to be lower in people with asthma and depression or anxiety. ${ }^{[4]}$

Adults, children and adolescents with asthma have a high prevalence of anxiety disorders. In adult populations with asthma, the estimated rate of panic disorder ranges from $6.5 \%$ to $24 \%$. Individuals with asthma appear to have about a twofold higher risk of having one or more anxiety or depressive disorders.[5] In a large population-based sample of adults, asthma was associated with a significantly increased likelihood of anxiety disorders (Especially panic, generalized anxiety disorder, and phobias) and affective disorders. Depressive symptoms are also very common in asthma. Severe asthma can be very demoralizing and lead to learned helplessness. 
In adults, particularly older adults, asthma is associated with higher rates of depression than other chronic illnesses, even after adjusting for psychosocial factors, physical comorbidity and the use of medications linked to depresssion.[6] Anxiety and depressive symptoms are common in patients with COPD, even when their disease is mild. Anxiety is also common in COPD and is related to some of the same factors described for asthma including the psychological response to the experience of breathlessness as well as side effects of $b$-agonists. Therefore, this study was designed to find out depression and anxiety disorder in patients of COPD and Bronchial Asthma in a tertiary care teaching hospital in Srinagar.

\section{AIMS \& OBJECTIVES \\ Aim}

To study the Psychiatric morbidities in patients of Chronic Obstructive Pulmonary Disease and Bronchial Asthma attending OPD of tertiary care hospital.

\section{Objectives}

To find out and study the socio-demographic profile and psychiatric morbidities using Hamilton depression rating scale (HAM-D) and Hamilton Anxiety rating scale (HAM-A) scales in patients presenting with COPD and Bronchial Asthma.

\section{MATERIALS AND METHODS}

Materials

1. Study Proforma: It consisted of a semi structured proforma to record the socio-demographic and respiratory status of the patient.

2. Hamilton Anxiety rating scale (HAM-A): HAM-A is one of the first rating scales developed to measure the severity of anxiety symptoms consists of 14 items. Each item has 4 options ranging from 0 (Not present) to 4 (Severe) with a total score ranging from $0-56$, where $<17$ indicates mild severity, 18-24 mild to moderate severity and 25-30 moderate to severe. The patient responds to each and can complete the questionnaire in 15 minutes or less. The clinician can quickly score the questionnaire and identify those patients whose scores suggest the presence of anxiety.[7]

3. Hamilton Depression rating scale (HAM-D): HAM-D is a designed to rate severity of depression in patients. It is to be administered by a health care profession. Although it contains 21 items, calculate the patients score on the first 17 answers. It has a total score of $88.0-7$ is considered to be normal, $8-13$ is mild, $14-18$ is moderate, $19-22$ is severe and $>23$ is very severe depression. ${ }^{[8]}$

4. Methodology

Study Site: Patients referred to the Department of Psychiatry of a tertiary care teaching hospital in Srinagar.

\section{Inclusion Criteria}

- Patients diagnosed with COPD and Bronchial Asthma referred to Psychiatry Department for evaluation.

- Patients between the ages of 30 to 90 years.

\section{Exclusion Criteria}

- Patients who did not give consent.

- Patients suffering from severe neurological illnesses.

- Patients suffering from severe psychiatric disorders.

\section{Method}

This was a hospital based cross-sectional observational study which included all referred patients with diagnosis of COPD and Bronchial Asthma to Department of Psychiatry for evaluation.

Successive patients satisfying the inclusion and exclusion criteria were taken up for the study and administered the Hamilton Anxiety rating scale (HAM-A) and Hamilton Depression rating scale (HAM-D) for evaluation of depression and anxiety.

Each patient was informed about the purpose of interview; his/her consent was obtained and strict confidentiality was ensured. The interview was conducted as soon as possible after the patient had satisfactorily recovered medically and was able to co-operate for the interview. Those patients referred to Psychiatry OPD for evaluation were interviewed in the outpatient department itself and other patients were interviewed in their respective wards of initial admission. General description, demographic data and psychiatric history were recorded using the self-designed proforma.

\section{Statistics}

Data was expressed in actual number, percentage and mean \pm standard deviation. The Chi -square test was used for categorical data with ' $p$ ' value less than 0.05 taken as statistically significant.

\section{Flow Chart}

Patient referred for psychiatric evaluation

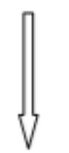

Patient fulfills inclusion and exclusion criteria

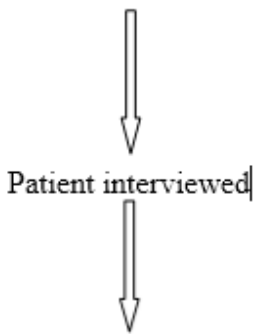

Recording of socio-demographic data

Assessment of Depression and Anxiety disorder by using HAM-A and HAM-D questionnaire

Data of 60 completed case record forms of patients collected Data analyzed bio statistically Results tabulated and discussed 


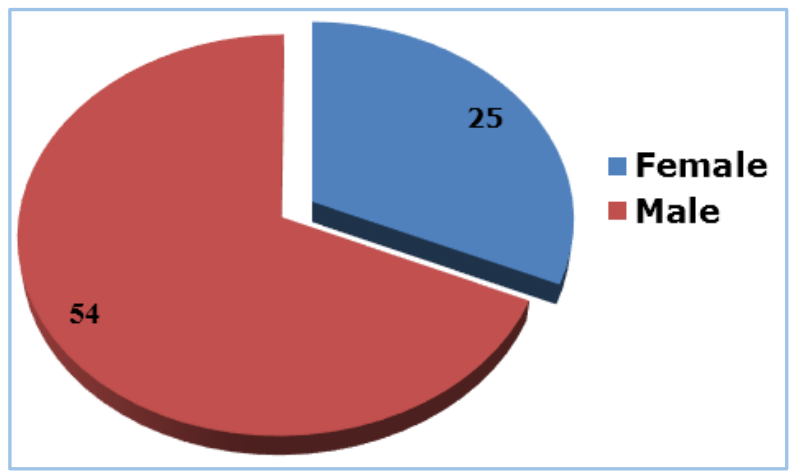

Fig. 1: Gender wise distribution of Patients of COPD and Bronchial Asthma

There were predominantly more males $(65 \%)$ than females (35\%). Male patients had more percentage of Bronchial Asthma and COPD as compared to females.

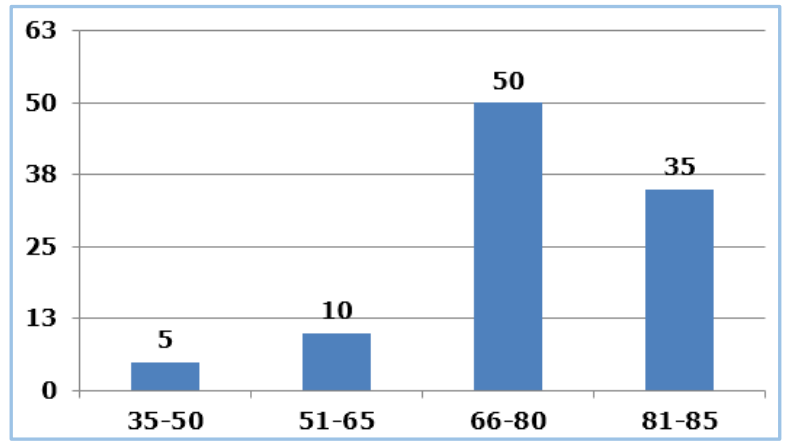

Fig. 2: Age wise distribution of patients of COPD and Bronchial Asthma

$5 \%$ of patients were in the age group of 35-50 years, $10 \%$ patients between $51-65$ years, $50 \%$ in the $66-80$ years age group and $35 \%$ patients in the $81-85$ years age group.

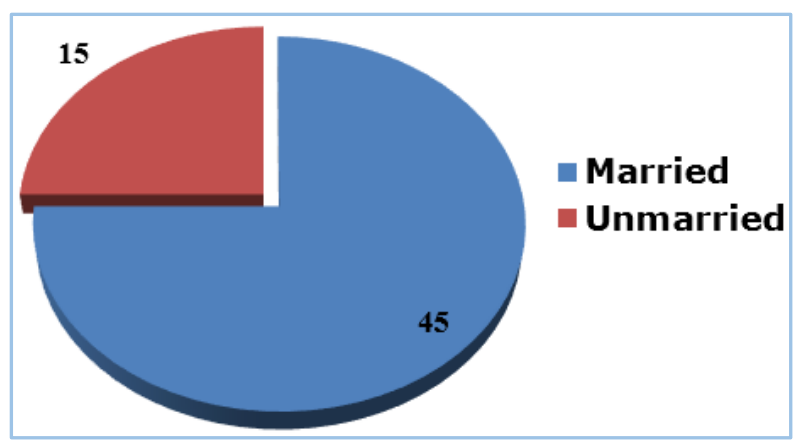

Fig. 3: Distribution of COPD and Bronchial Asthma Patients according to their Marital Status

$75 \%$ of the COPD and Bronchial Asthma patients were married and $25 \%$ were unmarried.

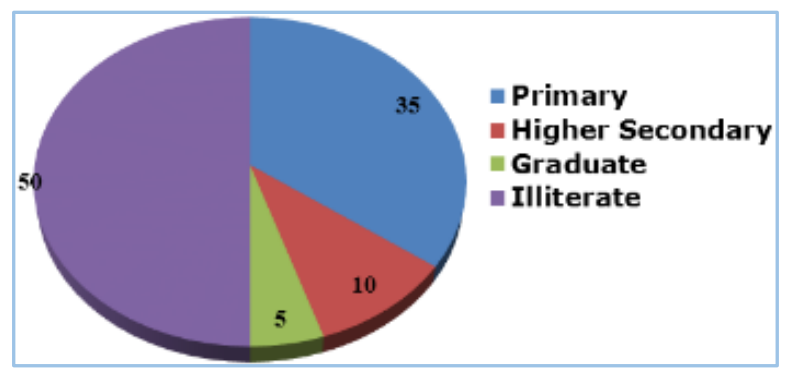

Fig. 4: Distribution of COPD and Bronchial Asthma patients as per their level of education
$50 \%$ of the patients were illiterate, while as $35 \%$ educated up to the primary level. $10 \%$ studied up to higher secondary while as $5 \%$ were graduate.

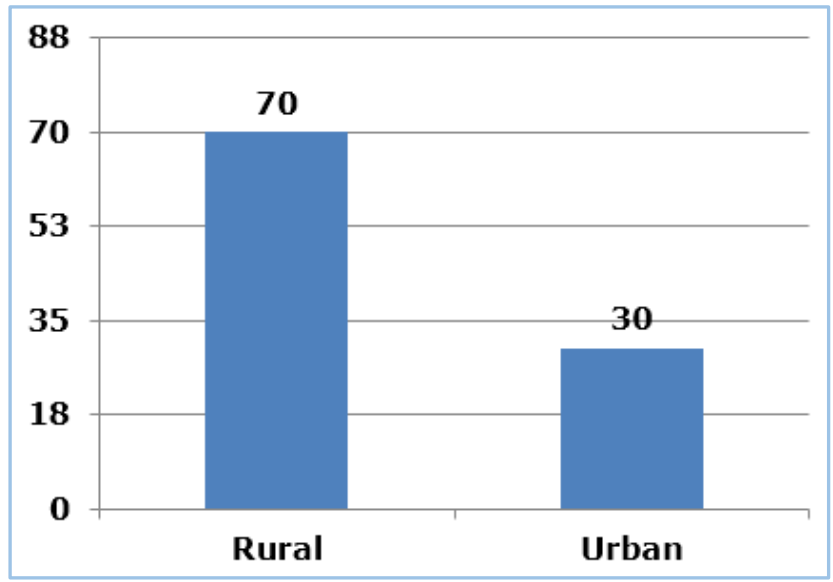

Fig. 5: Distribution of COPD and Bronchial Asthma patients as per their residence

$70 \%$ of the study sample resided in rural area while as rest of $30 \%$ resides in urban area.

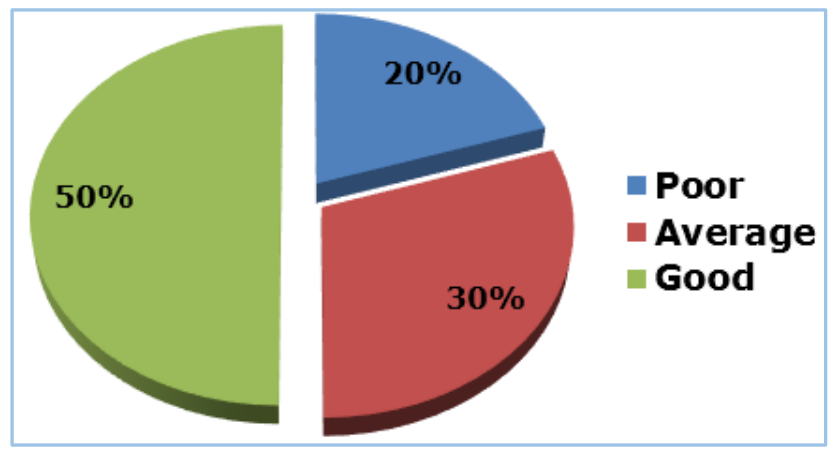

Fig. 6: Distribution of COPD and Bronchial Asthma Patients as per Financial Status

$50 \%$ of the patients had poor social and financial status, $30 \%$ had average and rest of $20 \%$ of patients had good social and financial status.

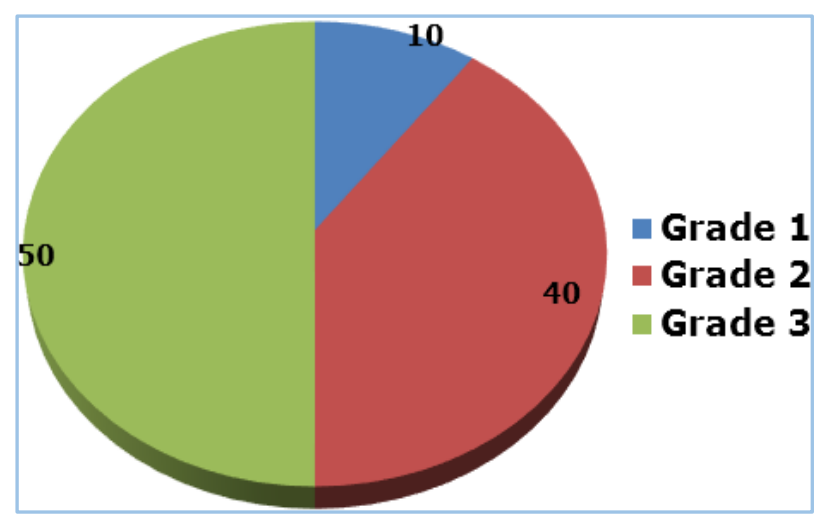

Fig. 7: Distribution of COPD and Bronchial Asthma patients according to Dyspnea

$50 \%$ of patients had grade 3 dyspnoea, $40 \%$ had grade 2 dyspnea and rest of $10 \%$ of patients had grade 1 dyspnea. 


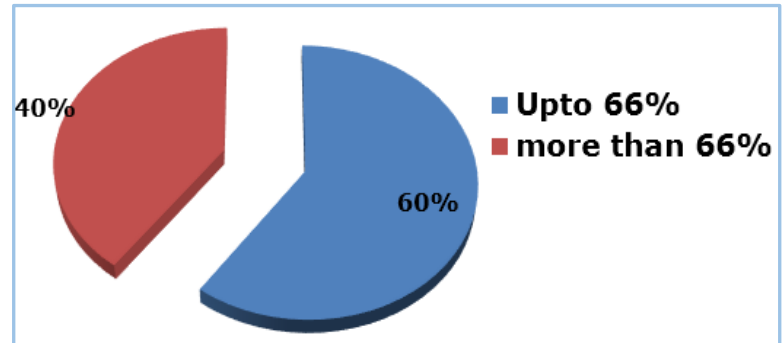

Fig. 8: Severity of disease (FEV1) \%

$60 \%$ of patients had (FEV1) $\%$ up to $66 \%$, while as $40 \%$ of patients had (FEV1) \% more than $66 \%$.

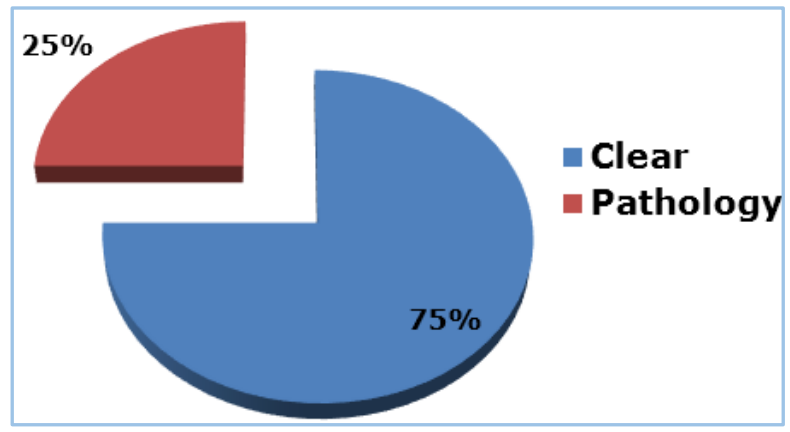

Fig. 9: Chest X-ray finding in patients of COPD and Bronchial Asthma

$75 \%$ of patients had clear chest X-ray while as $25 \%$ had some pathology.

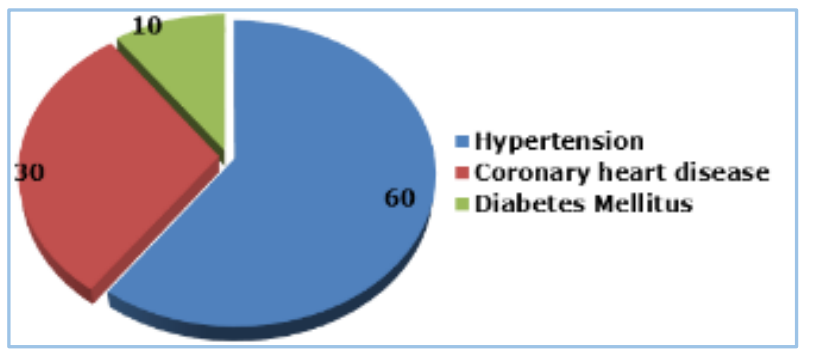

Fig. 10: Medical co-morbidities in patients of Bronchial Asthma and COPD

$60 \%$ of patients had co-morbid hypertension, $30 \%$ with coronary heart disease and 105 had diabetes mellitus.

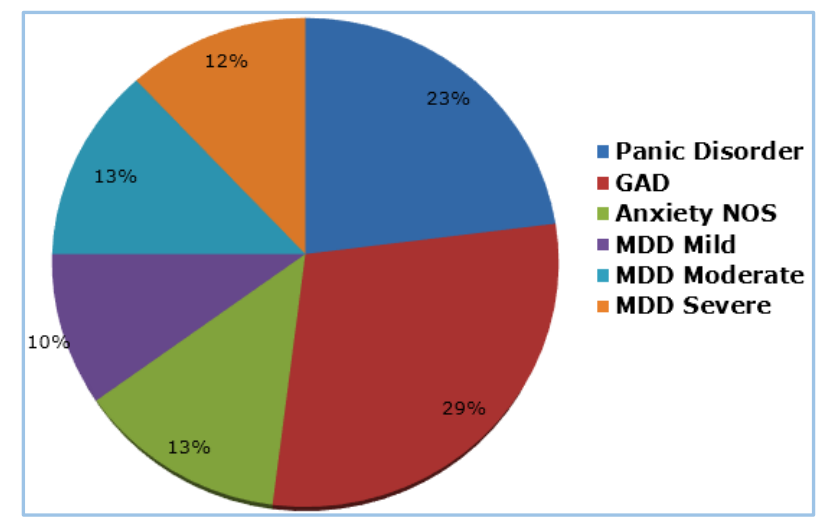

\section{Fig. 11: Psychiatric co-morbidity in patients} of COPD and Bronchial Asthma

$65 \%$ of patients were found to have predominant anxiety symptoms in which $23 \%$ has panic disorder followed by $29 \%$ with GAD, while rest of $35 \%$ had depressive symptoms in which $10 \%$ has mild form.

\section{DISCUSSION}

In this study an attempt has been made to find out the prevalence of depression and anxiety in patients of COPD and Bronchial Asthma in a tertiary care hospital Srinagar. Our study investigated the prevalence of both anxiety and depression disorders in male and female COPD and Bronchial Asthma patients with a wide range of disease severity. A recent study by Kunik et al. ${ }^{9}$ investigated the prevalence of anxiety and depression in a large sample of patients with chronic breathing disorders, including COPD, but the authors enrolled only patients who reported a significant level of anxiety and depression in a telephone screening. The significant findings of our study are as follows: (1) The prevalence of anxiety is very high as compared to depression in patients of both COPD and Bronchial Asthma; (2) Male patients have higher levels of anxiety and depression; (3) More patients had grade one dyspnoea followed by grade two and then grade one. Female patients appear to be more susceptible to psychological impairment.

There were predominantly more males (65\%) than females (35\%). Male patients had more percentage of Bronchial Asthma and COPD as compared to females. According to Fabiano Di Marco et al.10 females were having more percentage as compared to males. $75 \%$ of the COPD and Bronchial Asthma patients were married and 25\% were unmarried. $70 \%$ of the study sample resided in rural area while as rest of $30 \%$ resides in urban area. Representations of gender, religion, family type and marital status have been found to be in accordance with socio-demographic profile of our country. Our study shows $50 \%$ of patients had grade 3 dyspnea, $40 \%$ had grade 2 dyspnea and rest of $10 \%$ of patients had grade 1 dyspnea. $60 \%$ of patients had (FEV1) $\%$ up to $66 \%$, while as $40 \%$ of patients had (FEV1) $\%$ more than $66 \%$. C. P. Engström, L. O. Persson. ${ }^{11}$ et al, found out that fortysix patients with expiratory volume in one second (FEV1) below 50\% predicted showed particularly high levels of dysfunction. Van Ede et al. ${ }^{12}$ underlined the lack of studies having adequate sample sizes.

In our study $60 \%$ of patients had hypertension followed by coronary heart disease in $30 \%$ and $10 \%$ patients had diabetes mellitus. This is supported in the study done by Schellevis FG et al. ${ }^{13}$ with similar findings. A literature review on the prevalence of anxiety in COPD patients reported rates of anxiety ranging from $10 \%$ to $40 \% .^{14}$ in our study prevalence of anxiety ranges to $65 \%$ as compared to $35 \%$ with depression. $50 \%$ of the patients had poor social and financial status, $30 \%$ had average and rest of $20 \%$ of patients had good social and financial status $75 \%$ of patients had clear chest X-ray while as $25 \%$ had some pathology Out of sixty cases of COPD and Bronchial Asthma, fifty percent of the patients were in the age group of $66-80$ followed by $35 \%$ in age group of 81-85 years. This could suggest that COPD and Bronchial Asthma is a problem of old age. This is supported by the study done by Jennifer A Cleland, Amanda J Lee. ${ }^{15}$ et al which showed old age has an impact on COPD. Keeping in view the findings it becomes mandatory for treating physicians to keep in mind need for psychological evaluation of such patients. 


\section{CONCLUSION}

In this study we found that COPD and Bronchial Asthma was more common in old age people in this hospital based study. More than half of the patients were married with most of them being illiterate. More than $70 \%$ patients belonged to rural background. $50 \%$ of patients had poor financial status. $50 \%$ of patients had dyspnea of grade 3 severity, with FEV1 severity of up to $66 \%$ in $60 \%$ of patients.

$75 \%$ of patients had no finding in $\mathrm{x}$-ray chest while as remaining $25 \%$ showed pathology. All $100 \%$ of patients had a medical co-morbidity with hypertension found in $60 \%$ of patients followed by coronary heart disease in 30\% of patients and diabetes in 105 of patients. Depression was found in $35 \%$ of patients while $65 \%$ had anxiety disorder as comorbid diagnosis.

\section{REFERENCES}

1. Di Marco F, Santus P, Centanni S. Anxiety anddepression in asthma. Curr Opin Pulm Med 2011;17(1):39-44.

2. Waxmonsky J, Wood BL, Stern T, et al. Associationof depressive symptoms and disease activity inchildren with asthma: methodological and clinicalimplications. J Am Acad Child Adolesc Psychiatry 2006;45(8):945-954.

3. Laforest L, Van Ganse E, Devouassoux G, et al. Influence of patients characteristics and diseasemanagement on asthma control. J Allergy ClinImmunol 2006;117(6):1404-410.

4. Krommydas GC, Gourgoulianis KI, Angelopoulos NV, et al. Depression and pulmonary function in outpatientswith asthma. Resp Med 2004;98(3):220-224.

5. Kuehn B, Asthma linked to psychiatric disorders. JAMA 2008;299(2):158-160.

6. Ng TP, Chiam PC, Kua EH. Mental disorders andasthma in the elderly: a population- based study. IntJ Geriatr Psychiatry 2007;22(7):668-674.
7. Hamilton $\mathrm{M}$. The assessment of anxiety states by rating. Br J Med Psychol 1959;32(1):50-55.

8. Hamilton M. A rating scale for depression. J Neurol Neurosurg Psychiatry 1960;23(1):56-62.

9. Kunik ME, Roundy K, Veazey C, et al. Surprisingly high prevalence of anxiety and depression in chronic breathing disorders. Chest 2005;127(4):1205-1211.

10. Fabiano Di Marco, Massimo Verga, Manuela Reggente, et al. Anxiety and depression in COPD patients: The roles of gender and disease severity. Respiratory Medicine 2006; 100(10):1767-1774.

11. Engström CP, Persson LO, Larsson S, et al. Functional status and well-being in chronic obstructive pulmonary disease with regard to clinical parameters and smoking: a descriptive and comparative study. Thorax 1996;51(8):825-830. doi:10.1136/thx.51.8.825.

12. Van Ede L, Yzermans CJ, Brouwer HJ. Prevalence of depression in patients with chronic obstructive pulmonary disease: a systematic review. Thorax 1999;54 (8):688-69.

13. Schellevis FG, Van der Velden J, Van de Lisdonk E, et al. Comorbidity of chronic diseases in general practice. J Clin Epidemiol 1993;46(5):469-473.

14. Brenes GA. Anxiety and chronic obstructive pulmonary disease: prevalence, impact, and treatment. Psychosom Med 2003;65(6):963-970.

15. Jennifer A Cleland, Amanda J Lee, Susan Hall. Associations of depression and anxiety with gender, age, health-related quality of life and symptoms in primary care COPD patients. Oxford Journals Medicine \& Health Family Practice 2007;24(3):217-223. 